\title{
Managing selection of AFF power generation technologies in the internationally evolving carbon-free context
}

\author{
Andrius Tamosiunas ${ }^{1}$ \\ ${ }^{1}$ Faculty of Business Management, Vilnius Gediminas Technical University, Vilnius, Lithuania
}

\begin{abstract}
The article presents the analysis fossil fuel power generation market, focusing on management of advanced fossil fuel (AFF) power generation challenges of related technologies especially when tackling climate change impacts, complying with stricter environmental requirements. A wide and dynamic spectrum in scope and scale of factors revealed confirms the necessity for solutions enabling organizations to transform and manage rationally their fossil fuel-based business models towards greater competitiveness in the context of emerging renewable energy reliance. Nevertheless, in this respect the measures in question may require trade-offs, therefore when considering their combination, a diligent multicriteria analysis will inevitably be involved. With pivotal focus on the economic utility and the balanced and sustained strategic development of business, as the result of the research author proposes to apply VIKOR method when deciding on AFF power generation options. Application flexibility of the proposed method allow to evaluate, compare possible alternatives in a comprehensive and complex manner and to mingle MCDA tools if needed.
\end{abstract}

\section{Introduction}

Tackling the impacts of climate change need transforming business models in order to sustain their competitiveness. Reducing carbon dioxide (CO2) emissions in the European Union (EU) by at least $85 \%$ by 2050 compared to the 1990 [1] respectively stipulate as well business and its environment. Purposely testing four de-carbonization scenarios $[2,3$, 4], i.e., renewables, nuclear, carbon capture and storage (CSS) and energy efficiency) requires combining a variety of diverse measures into the well-coordinated system. The latter may vary, for instance, from fossil and biofuels to hydrogen and marine energy, from wind and solar to nuclear and geothermal, from upgrading traditional facilities to introducing advanced information and communication systems. Whereas measures may have disadvantages (e.g., in terms of safety and costs or limitations of scale, scope, and supply in comparison to conventional fossil fuel-based measures) considering their combination will inevitably be involving diligent multicriteria analysis. Respective specific scientific researches related to matching renewable energy as well as other energy efficiency measures are limited and fragmentary especially when concerning complex management decisions in concert with multi-criteria analysis.

Having in mind the context, the paper synthesizes a vast spectrum of empirical data and related literature attempting to approach systematically this matter analyzing, as the example, peculiarities of the use of AFF fuel power generation solutions. The definite focus is on improving, as a complex, a management of the selection process of AFF power generation technologies utilizing multi-criteria analysis tools. For this purpose, as the result of the research, the author proposes to use VIKOR method enabling to choose rationally most 
viable options in terms of convergent and sustained competitive growth for an organization or economy sector in question at state, county and municipal levels accordingly.

\section{Evolving fossil fuel power generation}

The research in question is built on author's empirical findings on fossil fuel-based energy solutions, carbon and energy markets development in EU as well as using databases of relevant international public institutions (of EU and the United States (US)) covering the period over the last 10-year. And as to the upshot, the empirical results are divergent. It seems that combustible fuels - coal, natural gas, oil - deliver almost $50 \%$ of EU's net electricity generation capacity nowadays and will consist the major part for at least two decades ahead $[2,3,4]$. While sharing more than $85 \%$ of global energy production $[3,4,5]$ the latter is projected to add some $45 \%$ of additional generation capacity by 2035 (10\% in the EU), delivering up to $47 \%$ of the electricity by $2035[2,5]$. Aiming at the global warming below $2{ }^{\circ} \mathrm{C}$ compared to the temperature in pre-industrial times while reaching Europe 2030 objectives the following tasks are due for fossil fuel-based power generation facilities as if justifying their future viability and efforts for further development [2, 3. 4, 5]:

- retrofitting old plants with available maturity while also adding biomass and (or) organic wastes combustion alternatives;

- constructing new plants basing on advanced technologies.

$84 \%$ (of which $37 \%$ - from power generation) of $\mathrm{CO}_{2}$ equivalent emissions of 2018 in the EU result from combustible fuels. $32 \%$ of $\mathrm{CO}_{2}$ equivalent emissions are from power generation. Hereby $50 \%$ of power generated in EU (and in most countries worldwide) in 2018 is of fossil fuels, of which coal and gas are the main sources (with $25 \%$ each). Respectively investing in energy efficiency measures and switching to renewable energy would make market participants less vulnerable to the dynamics of prices of fossil fuel energy sources. The latter decisions are of strategic context as they impact not only particular energy producer in question but also, directly and indirectly, related the market participants of various economy sectors as locally as internationally. For rationality of such decisions a maturity of the combustible fuels-based power generation infrastructure, its diverse capacity and potential in scope and scale are of pivotal focus. Hence it is crucial respectively to explore AFF power generation options. Hereby reasonably the latter can be classified in terms of types fuel and conversion technology of fuel chemical energy into to thermal (i.e.; conventional thermal, fluidized bed, internal combustion or gasification), a turbine used (e.g., gas turbine versus steam based) and conditions of steam generated. As to the last two decades also recent and expected evolution the technology configurations in question are, in principle, the following:

- advanced pulverized coal (APC) combustion for single and dual units,

- $\quad$ integrated gasification combined-cycle (IGCC) for single and dual units,

- natural gas combined-cycle (NGCC) conventional combustion

- NGCC with advanced gas turbine

- conventional combustion turbine.

According to the findings, the estimated capital and operating costs for power generation technologies from fossil fuels can be as given in Table 1. 
Table 1. Estimations of capital and operating costs for fossil fuel power generation

\begin{tabular}{|l|c|c|l|c|}
\hline Technology/capacity @ costs & $\begin{array}{l}\text { Capacity } \\
\text { (MW; } \\
\text { nominal) }\end{array}$ & $\begin{array}{l}\text { Capital cost } \\
(\text { EUR/kW) }\end{array}$ & $\begin{array}{l}\text { Operating \& } \\
\text { maintenance costs } \\
\text { (EUR/kW/year; } \\
\text { fixed) }\end{array}$ & $\begin{array}{l}\text { Operating \& } \\
\text { maintenance costs } \\
\text { (EUR/MWh; } \\
\text { variable) }\end{array}$ \\
\hline APC combustion for single units & 600 & 2500 & 28.9 & 3,4 \\
\hline APC combustion for dual units & 1200 & 2250 & 22 & 3,4 \\
\hline IGCC for single units & 550 & 3000 & 46 & 5,5 \\
\hline IGCC for dual units & 1300 & 2800 & 38 & 5,5 \\
\hline NGCC conventional combustion & 600 & 690 & 9 & 2,7 \\
\hline NGCC with advanced gas turbine & 350 & 770 & 11 & 2,4 \\
\hline Conventional combustion turbine & 80 & 745 & 5,5 & 11 \\
\hline
\end{tabular}

Source: author's collected data

Inevitably (for every de-carbonization scenario) emphasis of upgrading power plants should include adding biomass or waste as alternative fuel, however, considering prices of energy resources and the impact of their supply longevity and costs. In this respect summarizing findings, Figure 1 represents the range of average minimum and maximum estimations of energy sources extraction costs.

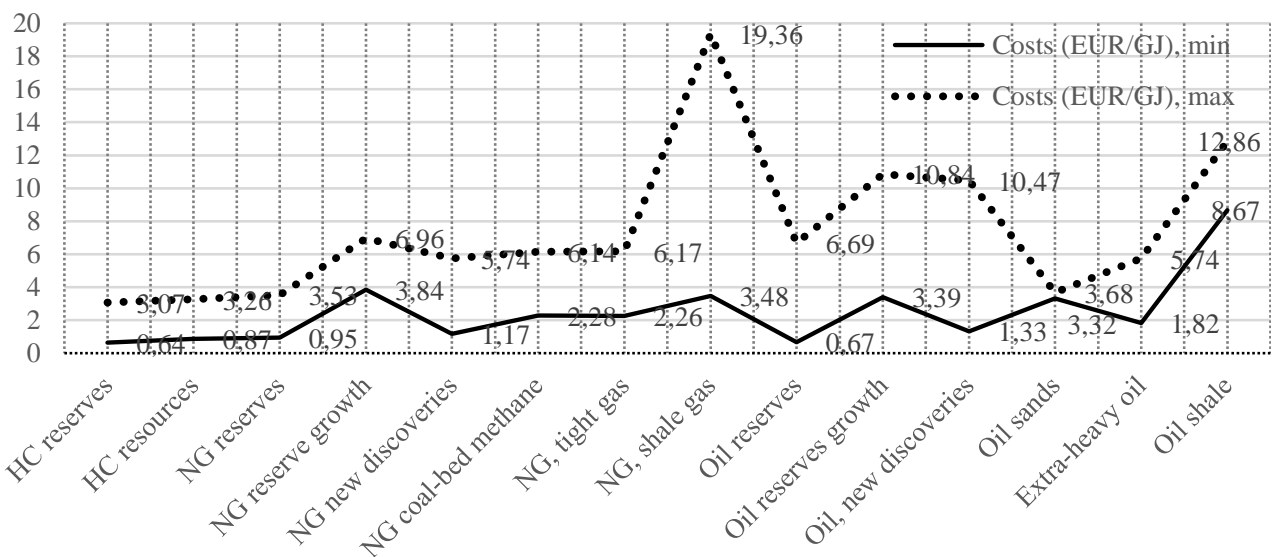

Fig. 1. Extraction costs of energy sources. Source: author's collected data. Note HC - hard coal, NG - natural gas.

Basing on the data of Figure 1 coal and oil are still the cheapest resources while undiscovered natural gas, oil as well as shale oil and gas are the expensive ones. In addition to the latter, evidently, the maturity of resource-specific technologies along with infrastructure let as well to reduce costs at least due to the proprietary learning curve and economy of scale.

In case of coal, over last several decades, pulverized coal, fluidized bed boilers (or gratefired boiler plants) operating at sub-critical pressure became dominant as in Europe as globally with rather low thermal efficiency (up to $38 \%$ of net lower heating value (with produced steam critical pressure - 22 megapascal (Mpa)) in comparison to evolving supercritical, ultra-supercritical or advanced ultra-supercritical power plants. In this context considering natural gas, especially for reducing SOx and nitrogen oxides (NOx) emissions, 
combined cycle plants have been definitely prevailing in electricity production over the last two decades. The latter has an average efficiency of 58\% (while simple cycle gas turbines $41 \%$ ) and marginally lower capital costs comparing to coal power plants (Table 1). In this respect, advanced air-cooled gas turbines are in focus with combined-cycle thermal efficiencies of $61 \%$ (single cycle - 40\% thermal efficiency). Further developments of an NGCC are aimed nowadays at reaching a combined thermal efficiency of $63 \%$ in $3-5$ years. Likewise, co-firing coal, syngas or biogas can be produced gasifying or processing biomass respectively and then adding natural gas or reformed natural gas. In terms of alternatives to natural gas combining horizontal drilling with hydraulic fracturing have made shale gas extraction doable (mainly in the US) however environmental concerns (at least in EU) are in focus for further investigations regarding overall safety and sustainability of commercial exploitation of such technologies. Moreover, the latter reasonably require modifications of regulatory measures on access to water resources and pipeline infrastructure, public and private initiatives as well as land ownership. In this respect well known European Union's Third Energy Package could be an example stipulating development of alternatives to fossil fuel power generation (incl. natural gas as per subject concerned). As the result, oil as a fuel for power generation is used only for security and sustainability reasons. In this context definitely, the use and further development of fossil fuel solutions will correlate with the strictness of regulatory measures and the accessibility of reserves. In this respect having in mind that coal reserves are greater than oil and natural gas globally [4], only integrating diverse technologies let complying with evolving regulatory measures and respectively maintaining the competitiveness of conventional fossil fuels-based power generating utilities. Further decarbonization actions [2, 3, 4] inevitably will stipulate the diversification of technologies for compliance with the use of renewable energy sources and greenhouse gas emissions targets. Consequently, fossil fuel share in power generation is expected to shift significantly from coal to gas (and renewables) while also sustaining nuclear power generation by $2050[3,4]$. Another factor affecting fossil fuel power generation is the $\mathrm{CO}_{2}$ price (Carbon emissions price per ton). As the result of regulatory measures, the latter was facing a sharp increase towards $\sim 16 \mathrm{EUR} / \mathrm{t}$ from $\sim 8 \mathrm{EUR} / \mathrm{t}$ during 6 months from 2017.12 to 2018.07 steadily reaching above 29EUR/t by the mid of July of 2019. Furthermore, there is an indisputable direct correlation of $\mathrm{CO}_{2}$ prices with dynamics of prices of fossil fuel-based energy resources (Fig 2).

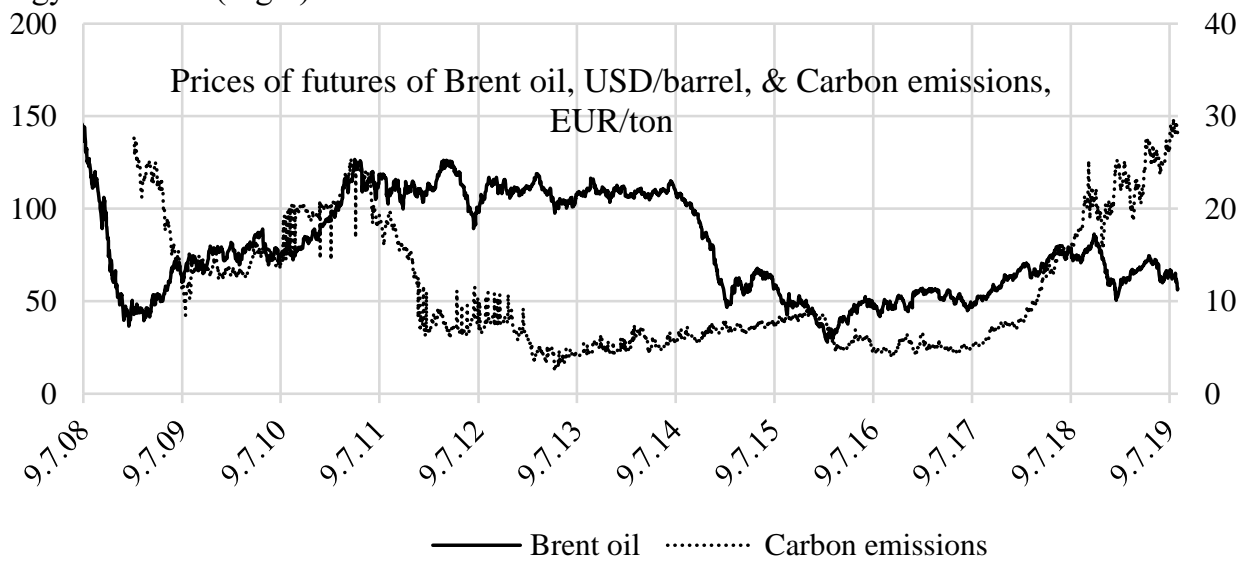

Fig. 2. $\mathrm{CO}_{2}$ and Brent oil future prices from 2008-07-09 to 2019-07-09. Source: author's collected data from the Intercontinental Exchange (ICE), the European Energy Exchange (EEX).

Consequently, the $\mathrm{CO}_{2}$ price fluctuations as to 2005-2019 period can be seen rather as a barrier for the development of AFF plants. The cost of $\mathrm{CO}_{2}$ emissions within the ETS will 
definitely impact the cost of electricity production and therefore a benefit of AFF may be challenged by increasing investment cost and efficiency reduction. Inevitably, $\mathrm{CO}_{2}$ price dynamic (Fig. 2) confirms the need for long-term emissions reduction policies in order to ensure the commercial viability of AFF based solutions (as well as renewables-based ones). Furthermore, the maturity of these technologies, their network, and the resulting proprietary curve play a vital role in sustaining technology transformation. In addition to that, a depletion of the resources requires to use a combination of fuels and respectively greater technical and managerial flexibility.

Such an extensive and vibrant range of above analyzed factors reveals the need for measures enabling organizations to wisely manage their fossil fuel-based business models under the circumstances of fluctuating commodity prices, emerging regulatory frameworks and renewable energy development.

\section{Improving management of the selection process}

The technology selection (i.e., AFF) shall unadventurously be related to investment transforming assets into particular deliverables proving qualitative and quantitative advancement. But the latter need to consider a rationality of actions, social processes as well as shared value creation (including, as the result, the inevitable restructuring [8] of organizations (as private as public). The insight hereby is that the investment in question is an open system interacting with its business market participants and influencing their progress.

In this respect, deciding on AFF power generation technology is a rather puzzling in terms of possible organization strategy changes, its business model and all the parties concerned. There are reasons for that. At the outset, traditionally the decisions are made based upon the experience and available information, which is often incomplete and (or) outdated due to ongoing technology progress as mentioned in the chapter above. Therefore, using curtailed and outmoded data do not add to the rationality of the selection process (especially when considering a wide-ranging quantitative valuation). Also, the fairness of the choice is bound by the diversity of criteria thus the selection is rather a multiple criteria task. For instance, (as to the practical experience of the last 20 years including observations and findings of the research in question) when managing the selection process there can be up to 30 various criteria used, consisting of quantitative and qualitative ones [6, 7]. For thorough, multifaceted assessment and synthesis under this circumstance sophisticate the selection task in a methodical sense. In order to solve this task, while dealing with large amounts of diverse and dynamic data (as revealed in para 1), the decision makers, when managing the selection process, inevitably need to involve multi-criteria decision analysis (MCDA) measures.

\section{Selecting MCDA}

There are various MCDA methods (with their alterations), for instance AHP [9] and MACBETH [10], COPRAS and PROMETHEE [11, 12; 13, 14], TOPSIS and VIKOR [15, 16]. The selection of MCDA method will depend as on complexity as on variability of a solution, also simplicity of application of MCDA method as well as the skills needed for objective and transparent selection, as well as the time parameters and reliability of the complete process.

The vital necessity for judiciously managing a selection involving any MCDA method is to set up a performance matrix. Each row of such matrix should be representing an option (i.e., let $O=\left\{\mathrm{O}_{1}, \mathrm{O}_{2}, \mathrm{O}_{3}, \Lambda, \mathrm{O}_{m}\right\}$ (1) be, for example, a set of m investment options) and every column delineating the performance of the options compared to each weighted 
criterion (i.e., subject to $C=\left\{C_{1}, C_{2}, C_{3}, \Lambda, C_{m}\right\}$ (2), a set of n criteria whose weights sustaining $w_{j} \in[\mathbf{O}, \mathbf{1}], \sum_{j=1}^{n} w_{j}=\mathbf{1}$ (3)). Having in mind the revealed dynamism and complexity of the subject in question an assessment of option performance could be as quantitative as qualitative. This challenge a consistency of the latter thus for proper comparison a normalization of data is inevitable. The decision makers must resolve on the extent to which objectives shall be met by the entries in the performance matrix. Although processing the data can be effective and quick, nevertheless, the risk to use unjustified assumptions, affecting the ranking of options (and, as the result, a final choice) is possible. As to ensure rationality of judgments to be made during the analysis and assessment of alternatives as well as for the reliability and effectiveness of overall selection process the author proposes to apply the selection management cycle (Fig. 3) consisting of the following tasks: setting up an evaluation unit; data collection \& analysis; setting up evaluation criteria and weighting; generating alternatives; evaluating possible alternative solutions in terms of criteria; applying a normative MCDA method(s); accepting "the best" alternative as an "optimal" (preferred); if selection results not accepted, evaluation unit iterates all the steps from the beginning.

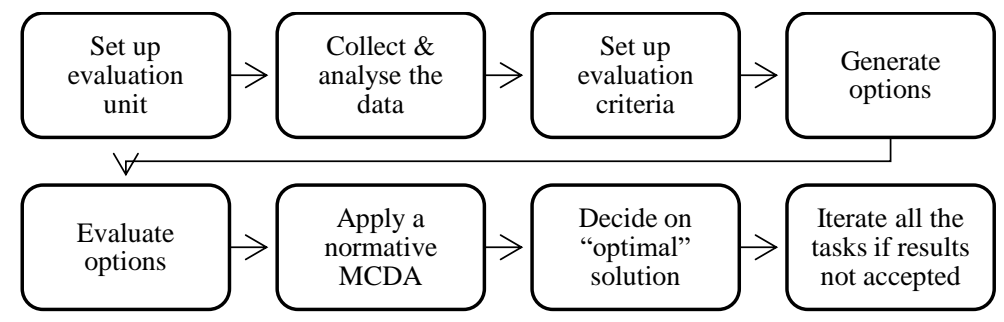

Fig. 3. Selection management cycle. Source: author.

Considering the variety of MCDA methods as mentioned above, the author recommends to use VIKOR MCDA method $[15,16]$ due to the following reasons:

- the latter allows selecting feasible compromise (with possible mutual concessions) solution (even with conflicting criteria) the closest to the ideal one.

- the method in question also abide further discussions, negotiations (e.g., reconsidering criteria, their weights), if needed, among evaluation unit members and (or) final decision makers.

There has to be noted that application of the VIKOR is based on the $L_{p}$ - metric (see

Eq. (4)) as an aggregating function applying, in principle, Euclidean distance approach as considered as well by Zeleny [17]:

$$
L_{p i}=\left\{\sum_{j=1}^{n}\left[\left(f_{j}^{*}-f_{i j}\right) /\left(f_{j}^{*}-f_{j}^{-}\right)\right]^{p}\right\}^{1 / p} 1 \leq p \leq \infty ; i=1,2,3, \ldots, m .
$$

For example, in the VIKOR method $L_{1, i}$ (as $S_{i}$ ) and $L_{\infty, i}$ (as $R_{i}$ ) are used to formulate order of preferences. The solution obtained by $\min S_{i}$ is with a maximum group utility ("majority" rule), and the solution obtained by $\min R_{i}$ is with a minimum individual regret of the "opponent". Assuming that each alternative is evaluated by each criterion function, the compromise ranking could be performed by comparing the measure of closeness to the ideal alternative. The various $m$ alternatives are denoted as $A_{1}, A_{2}, A_{3}, \ldots, A_{m}$. For alternative $A_{i}$, the 
rating of the $j$ th aspect is denoted by $f_{i j}$, i.e. $f_{i j}$ is the value of $j$ th criterion function for the alternative $A_{i} ; n$ is the number of criteria.

Accordingly, the calculated values $S_{i}$ (utility measure), $R_{i}$ (regret measure) and the values $Q_{i}$ (maximum group benefits) can be ranked (Table 2).

Table 2. Results of comparison of AFF power generation technologies

\begin{tabular}{|l|c|c|c|c|c|c|}
\hline Technology/variable & $S_{i}$ & $R_{i}$ & $S_{i}$ normalized & $R_{i}$ normalized & $Q_{i}$ & Rank \\
\hline $\begin{array}{l}\text { APC combustion for } \\
\text { single units }\end{array}$ & 0.411 & 0.056 & 0.379 & 0.500 & 0.881 & 4 \\
\hline $\begin{array}{l}\text { APC combustion for } \\
\text { dual units }\end{array}$ & 0.436 & 0.056 & 0.394 & 0.500 & 0.893 & 5 \\
\hline $\begin{array}{l}\text { IGCC for single } \\
\text { units }\end{array}$ & 0.692 & 0.056 & 0.783 & 0.500 & 1.206 & 6 \\
\hline IGCC for dual units & 0.834 & 0.056 & 0.913 & 0.500 & 1.371 & 7 \\
\hline $\begin{array}{l}\text { NGCC conventional } \\
\text { combustion with }\end{array}$ & 0.178 & 0.056 & 0.104 & 0.500 & 0.607 & 2 \\
\hline $\begin{array}{l}\text { NGCC } \\
\text { advanced gas turbine }\end{array}$ & 0.089 & 0.047 & 0.000 & 0.000 & 0.000 & 1 \\
\hline $\begin{array}{l}\text { Conventional } \\
\text { combustion turbine }\end{array}$ & 0.357 & 0.056 & 0.314 & 0.500 & 0.814 & 3 \\
\hline
\end{tabular}

Basing upon the calculated values $S_{i}$ (utility measure), $R_{i}$ (regret measure) and the values $Q_{i}$ (maximum group benefits) for the fossil fuel power generation technology options the following hierarchy of favorability of technologies is considered (Table 2): NGCC with advanced gas turbine is the best choice, NGCC conventional combustion is the second best solution and conventional combustion turbine is the third best. Consequently, hereby it can be stated that the suggested method is useful when analyzing, assessing, comparing, ranking the AFF power generation technologies and deciding on the most favourable one in economic terms. Definitely, in this respect, the latter may contribute when assessing the appropriateness of institutional and regulatory instruments especially in terms of justifying the use of fossil fuel-based power generation technologies as in private as in public organizations. As the result, public and private organizations can consider combining technologies for performance efficiency along with leading to secular and convergent economy models.

\section{Conclusions}

The fossil fuel power generation market is vigorously evolving due to technology progress, regulatory shifts and competition. Considering a challenging business environment, the proposed solution for managing the selection of fossil fuel power generation technologies is useful in terms of the following:

contributing to situation analysis when determining AFF power generation options and assessment criteria.

improving assessment and selection task rationally using suggested VIKOR method. In this respect, the results of the practical application of VIKOR for assessing options demonstrated flexibility in the use of the proposed tool and potentials to apply (also in concert, if needed) other MCDA tools.

The results of the paper could contribute to the inputs of further research on themes related as to fossil fuel-based as to renewable energy generation technologies, for instance, investigating aspects of combining the latter to the specifics of business models of public and private organizations as well as economy sectors at state, county and municipal levels. 


\section{References}

1. UNFCC. Paris Agreement. 27 pp. (2016)

2. EC. Energy Roadmap 2050. COM (2011)885/2, 24 p. (2011)

3. EC. Reflection paper. Toward sustainable Europe by 2030. COM (2019)22, 132 p. (2019)

4. IEA. World energy outlook. 507 p. (2018)

5. WEC. World energy issues monitor 2019. 208 p. (2019)

6. Ch. Hurson, Y. Siskos, A synergy of multicriteria techniques to assess additive value models. European Journal of Operational Research 238, 540-551 (2014).

7. R. Gudauskas, A. Kaklauskas, S. Jokūbauskienè, V. Targamadzè, L. Budrytè, J. Čerkauskas, A. Kuzminskè, Advisory, negotiation and intelligent decision support system for leadership analysis. International Journal of Computers, Communications \& Control 10, 667-677 (2015).

8. A. Tamošiūnas, The integrative management model for restructuring Small and Medium-sized Enterprises (SME). E\&M Ekonomie a management=E\&M Economics and Management 20, 36-51 (2017).

9. L. Scholten, N. Schuwirth, P. Reichert, J. Lienert, Tackling uncertainty in multicriteria decision analysis - an application to water supply infrastructure planning. European Journal of Operational Research 242, 243-260 (2015).

10. C. Bana e Costa, J. De Corte, J. Vansnick, MACBETH. International Journal of Information Technology and Decision Making 11, 359-387 (2012).

11. M. R. B. Behzadian, K. A. Albadvi, M. Aghdasi, PROMETHEE: a comprehensive literature review on methodologies and applications. European Journal of Operational Research 200, 198-215 (2010).

12. S. Corrente, J. Rui Figueira, S. Greco, The SMAA-PROMETHEE method. European Journal of Operational Research 239, 514-522 (2014).

13. RJ Yang, PXW Zou, J. Wang, Modelling stakeholder-associated risk networks in green building projects. International Journal of Project Management 34, 66-81 (2016).

14. M.F. Norese, A model-based process to improve robustness in Multicriteria Decision Aiding interventions. Journal of Multi-Criteria Decision Analysis 23, 183-196 (2016).

15. S. Opricovic, G-H. Tzeng, Extended VIKOR method in comparison with outranking methods. European Journal of Operational Research 178, 514-529 (2007).

16. S. Opricovic, Fuzzy VIKOR with an application to water resources planning. Expert Systems With Application 38, 12983-12990 (2011).

17. M. Zeleny, Multiple criteria decision making (MCDM): from paradigm lost to paradigm regained? Journal of multi-criteria decision analysis 18, 77-90 (2011). 